\title{
Neonatal Cytokines and Cerebral Palsy in Very Preterm Infants
}

\author{
KARIN B. NELSON, JUDITH K. GRETHER, JAMES M. DAMBROSIA, EILEEN WALSH, \\ SHAWN KOHLER, GOWRI SATYANARAYANA, PHILLIP G. NELSON, \\ BENJAMIN F. DICKENS, AND TERRY M. PHILLIPS
}

\begin{abstract}
Neuroepidemiology Branch [K.B.N.] and Biostatistics Branch [J.M.D.], National Institutes of Neurological Disorder and Stroke, Bethesda, MD 20892, U.S.A.; California Birth Defects Monitoring Program [E.W., J.K.G.] and Environmental Health Investigations Branch [J.K.G.], California Department of Health

Services, Oakland, CA 94612, U.S.A.; Immunochemistry Laboratory [B.F.D.], George Washington University Medical Center, Washington, DC 20037, U.S.A.; Laboratory of Developmental Neurobiology [S.K., G.S., P.G.N.], National Institute of Child Health and Human Development, Bethesda, MD 20892, U.S.A.; and DBEPS [T.M.P.], National Institutes of Health, Bethesda, MD 20892, U.S.A.
\end{abstract}

\begin{abstract}
To examine the relationship of cytokines in blood of very preterm neonates with later diagnosis of spastic cerebral palsy (CP) compared with infants of similar gestational age without $\mathrm{CP}$, we measured concentrations of inflammatory cytokines and other substances in archived neonatal blood by recycling immunoaffinity chromatography. Subjects were surviving children born before 32 wk gestational age (GA) to women without preeclampsia, 64 with later diagnoses of $\mathrm{CP}$ and 107 control children. The initial analyses were augmented by measurement of 11 cytokines by a bead-based flow analytic system (Luminex) in an additional 37 children with $\mathrm{CP}$ and 34 control children from the same cohort. Concentrations of examined substances did not differ by presence of indicators of infection in mother, infant, or placenta. On ANOVA, concentrations of a number of cytokines were significantly related to neonatal ultrasound abnormalities (periventricular leukomalacia, ventricular enlargement, or moderate or severe germinal matrix hemorrhage). None of the sub-
\end{abstract}

\section{ABSTRACT}

stances measured either by immunoaffinity chromatography or flow analytic methods, including IL-1, -6 , and -8 and tumor necrosis factor- $\alpha$, was related to later diagnosis of $\mathrm{CP}$ or its subtypes. Inflammatory cytokines in neonatal blood of very premature infants did not distinguish those with later diagnoses of CP from control children. (Pediatr Res 53: 600-607, 2003)
CP, cerebral palsy
GA, gestational age
PVL, periventricular leukomalacia
TNF, tumor necrosis factor
CSF, colony-stimulating factor
IFN, interferon
VIP, vasoactive intestinal peptide
VEGF, vascular endothelial growth factor
MIP, macrophage inflammatory protein

Abbreviations
Clinical and placental histologic markers of inflammation are common in preterm infants, especially in infants of the lowest gestational ages $(\mathrm{GA})(1,2)$. Intrauterine exposure to infection is an important cause of preterm birth $(3,4)$, and preterm infants are at high risk for cerebral palsy $(\mathrm{CP})(5,6)$.

Because intrauterine exposure to infection is a risk factor for development of CP in infants who are born at or near term (7-9), it is reasonable to wonder whether infants who are born very preterm with clinical indicators of intrauterine infection are at higher risk of CP than infants who are born at similar GA

Received April 11, 2002; accepted September 16, 2002.

Correspondence: Karin B. Nelson, M.D., NIH Clinical Center, Room 5S221, Bethesda, MD 20892-1447, U.S.A.; e-mail: knelson@helix.nih.gov

This work was supported in part by funds provided by the March of Dimes/Birth Defect Foundation.

DOI: 10.1203/01.PDR.0000056802.22454.AB and are free of markers of infection. Current evidence as to whether markers of infection are related to $\mathrm{CP}$ risk in infants who are born before $32 \mathrm{wk}$ GA is inconsistent, and studies differ widely in the frequency with which they identify the presence of intrauterine infection using clinical indicators (10).

Biochemical mediators of inflammation, such as cytokines, might be more sensitive markers of infection than are clinical signs and might offer clues to pathophysiology. A number of studies in perinatal medicine have used concentrations of inflammatory cytokines as indicators of possible infection.

In studies of predominantly term-born children with CP (11) and in term infants who died or developed CP (12), concentrations of inflammatory cytokines in neonatal blood were higher than in control infants. High cytokine levels were associated with clinical and histologic indicators of maternal or placental infection (10). Thus, both clinical and biochemical 
markers of inflammation have been linked with CP risk in children who were born at or near term.

In infants who were born before $36 \mathrm{wk}$ GA, Yoon et al. (13) reported higher median concentrations of certain inflammatory cytokines in the amniotic fluid of infants with evidence of periventricular leukomalacia (PVL), a predictor of $\mathrm{CP}$, on neonatal ultrasonographic examination. That group also reported a relationship of amniotic fluid cytokine concentrations with later diagnosis of CP (14). In a small group of children who were born before $32 \mathrm{wk}$ GA, Baud et al. (15) did not find a relationship between cytokine concentrations in amniotic fluid and PVL. Duggan et al. (16) did but Minagawa et al. (17) did not find a relationship between IL-1, -6 , and -10 and tumor necrosis factor- $\alpha$ (TNF- $\alpha$ ) in cord blood and neonatal brain imaging abnormalities, although they did note an association of IL-18 concentration with ultrasound abnormalities.

To investigate the association of cytokine concentrations with development of $\mathrm{CP}$ in a cohort of infants who were born before $32 \mathrm{wk}$ GA, we used recycling immunoaffinity chromatography to measure cytokines in archived neonatal blood drawn for state-mandated metabolic screening. To compare these results with cytokine determinations by assay methods that are more widely available, we used flow analytic methods to measure cytokines in an additional group of subjects from the same cohort of infants who were born before $32 \mathrm{wk}$ GA. We also examined the association of cytokine concentrations with abnormalities reported in neonatal cranial ultrasonography. Risk of CP is lower in preterm infants who are born to preeclamptic women (18-20); progeny of preeclamptic women were excluded from both case and control groups in this study.

\section{METHODS}

The study population included singleton children who survived at least to $2 \mathrm{y}$ of age, were born before $32 \mathrm{wk} \mathrm{GA}$, and had birth weight $<2000 \mathrm{~g}$. Births were between 1988 and 1994 at hospitals that offer level 2 or level 3 neonatal intensive care in the San Francisco Bay Area or Northern and Central San Joaquin Valley of California. Final diagnosis of $\mathrm{CP}$ and determination of case or control status was at age $4 \mathrm{y}$ or at the time of death for children who died between 2 and 4 y of age. Children who were born to women with preeclampsia or severe systemic disease or were born within $3 \mathrm{~h}$ of admission were excluded unless there was clinical evidence of intrauterine or maternal renal infection.

$\mathrm{CP}$ was defined as a chronic disability of CNS origin, characterized by aberrant control of movement or posture, appearing early in life, and not the result of a progressive disease. We excluded children who acquired their $\mathrm{CP}$ from illness or injury after the first month of life and those whose CP followed congenital TORCH infection with toxoplasma, rubella, cytomegalovirus, and herpes virus. Children with $\mathrm{CP}$ included in this study were identified by the California Children's Services and Department of Developmental Services. Charts of children from California Children's Services were reviewed by the authors to see that they met criteria for diagnosis. For children from Department of Developmental
Services, diagnostic information abstracted from charts was available in a standardized form. Controls were children who were not receiving special services for $\mathrm{CP}$ and met the same birth weight and GA criteria and with similar birth weight and GA distributions as cases. Additional details of case definition and control selection are provided elsewhere (21).

For obtaining a similar birth weight distribution for case and control children, the pool of controls was divided into $250 \mathrm{~g}$ birth weight strata by birth year, based on birth weight as recorded on the birth certificate. Two controls per case were randomly sampled from within each birth weight-birth year stratum. GA criteria would have been preferred, but the recording of GA on birth certificates is known to be unreliable.

Clinical data collection. Detailed labor, delivery, and neonatal medical record abstraction was conducted blinded to case-control status. For women who were medically transported to the delivery hospital, the medical record from the transporting hospital was obtained. Records were obtained from the receiving hospital for neonates who were transported from the delivery hospital within the neonatal period (typically from a level 2 to a level 3 facility).

GA was derived from measures in the mothers' hospital charts and known before delivery, giving priority to dates established early in pregnancy and to ultrasound examinations performed before 19 wk GA. Maternal race/ethnicity was according to mother's self-identification as recorded on the infant's birth certificate. Standards for fetal growth and birth weight for GA were derived from vital record data, classified by plurality, sex, and race, on $>1$ million births in California, 1966 through 1970 (22).

Our original study from this population was designed to evaluate tocolytic therapy. For maximizing efficiency in data collection, extensive clinical information was abstracted only on mother-infant pairs for whom the question of tocolytic treatment was relevant, i.e. those for whom delivery took place $>3 \mathrm{~h}$ after admission in the absence of preeclampsia, pregnancy-induced hypertension, or a severe systemic disorder or previous surgery that would determine the management of delivery.

Indicators of maternal infection include clinical diagnoses, signs and symptoms of infection during the admission for delivery up to $24 \mathrm{~h}$ postpartum, culture data, treatment with anti-infective medications, and placental pathology findings. Presence or absence of clinical conditions in mothers and infants was as recorded by physicians who cared for the patients. Copies of all available placental pathology reports were reviewed and coded by an expert placental pathologist blinded to case status. Blood spots on dried filter paper were obtained from the California Genetic Disease Program under a protocol approved by the California Committee for the Protection of Human Subjects.

Biochemical analysis. A 5-mm circle was punched from each blood spot dried on filter paper, and material was eluted as previously described $(23,24)$. The total protein content of each sample was measured and normalized to $1 \mu \mathrm{g} / \mathrm{mL}$ with phosphate buffer solution ( $\mathrm{pH} 7.4$ ), then labeled by mixture of $25 \mu \mathrm{L}$ of each sample with an equal volume of a light-emitting fluorochrome, Cy5 (Amersham Pharmacia Biotech, Piscat- 
away, NJ, U.S.A.). Labeled samples were held in microtiter plates at $4^{\circ} \mathrm{C}$ until use.

Samples were analyzed using recycling immunoaffinity chromatography $(25,26): 25 \mu \mathrm{L}$ of each sample was injected into a BioCad Sprint chromatography system equipped with a scout column selector (Perkin-Elmer, PerSeptive Biosystems, Foster City, CA, U.S.A.) to which was coupled a panel of small biocompatible immunoaffinity columns (Upchurch Scientific, Oak Harbor, WA, U.S.A.). These columns were packed with glass beads, 150-212 $\mu \mathrm{m}$ (Sigma Chemical Co., St. Louis, MO, U.S.A.), coated with immobilized antibodies to specific analytes (R \& D Systems, Minneapolis, MN, U.S.A.; Chemicon International, Temecula, CA, U.S.A.). Panels were arranged so that samples could pass through each column in a serpentine manner. During this phase, each column extracted a single analyte while allowing the nonreactive materials to pass to the next column. After passage through the columns, nonreactive materials were collected for further analysis. The bound analytes were recovered by acid elution of each column sequentially, measuring the released analyte by laser-induced fluorescence. Concentrations of each recovered analyte were calculated by comparison to standard curves constructed by running known amounts of pure analyte through identical conditions.

Substances measured were IL-1 through IL-13; TNF- $\alpha$; transforming growth factor- $\beta$; colony-stimulating factors (CSF) G, M, and GM; interferon- $\gamma$ (IFN- $\gamma$ ); calcitonin generelated peptide; vasoactive intestinal peptide (VIP); antithrombin III; vascular endothelial growth factor (VEGF); regulated on activation normal T-cell expressed and secreted; macrophage inflammatory protein (MIP) $1 \mathrm{a}$ and $1 \mathrm{~b}$; and monocyte chemotactic protein 1 and 2 .

Blinded replications of analyses for IL-1, 6, 8, and 9 and TNF- $\alpha$ were performed for 20 specimens, from 10 children with $\mathrm{CP}$ and 10 control children. The average percentage difference between values on the two assays ranged from $7 \%$ to $16 \%$. Paired $t$ tests revealed no significant differences between first and second determinations.

After analysis by recycling immunoaffinity chromatography, we examined blood spot eluates from an addition 37 children with $\mathrm{CP}$ and 34 controls drawn from the same birth cohort, using Luminex LabMAP (Austin, TX, U.S.A.) flow analytic methods $(25,26)$. The recycling immunoaffinity methodology uses single, often polyclonal, capture antibodies and may recognize partially degraded molecules that would be undetected by a double-antibody sandwich assay such as used in the Luminex analyses. However, use of the second paired antibody as in the Luminex methods enables greater specificity than use of the single-capture antibody.

The Linco kit (St. Charles, MO, U.S.A.) was used for 19 children with $\mathrm{CP}$ and 19 control children; the kit from Upstate Inc. (Lake Placid, NY, U.S.A.) was used for the remainder. Both the Linco and Upstate kits contained beads coated with antibodies for IL-1 $\beta,-2,-4,-6,-8,-10$, and -12; GM-CSF; IFN- $\gamma$; and TNF- $\alpha$; and the Linco kit also contained beads coated with antibodies for IL-5. Assays were performed according to the manufacturers' instructions; samples were run in duplicate on the Linco assays and singly on the Upstate assay.
Concentrations of individual analytes were calculated assuming a constant volume of blood on each spot or expressed per microgram of protein in each sample. The results and conclusions were not altered by the method of normalization.

Statistical analysis. The estimation of sample size required was based on results of a previous study of mostly term infants in which marked case-control differences were observed; the current study was approximately twice as large as the earlier study. Case-control comparisons of continuous measurements were by nonparametric Mann-Whitney $U$ tests, and comparisons of categorical factors were by Fisher exact tests. The association of analyte concentrations with GA, birth weight, and day of blood draw were examined in linear regression models. The similarity of concentrations of the analytes in children with $\mathrm{CP}$ and in control children are obvious, and adjustments for multiple testing were not used for these comparisons. For the analysis of variance, models with $\mathrm{CP}$ and ultrasound abnormalities as main effects and selected analyses as response adjustments for multiple testing were accomplished using Scheffe's pairwise comparisons.

\section{RESULTS}

A total of 170 children with $\mathrm{CP}$ and 288 control children met study criteria. Archived neonatal blood was examined by ultramicroimmunoassay for a randomly selected subgroup of these, consisting of 64 children with $\mathrm{CP}$ and 107 control children. Blood was drawn, on average, $2.4 \mathrm{~d}$ after birth both in children with later $\mathrm{CP}$ diagnoses and in controls. Among children with $\mathrm{CP}$, subtype was unrecorded in two; of the 62 known, 33 (53\%) had spastic diplegia, 20 (32\%) had spastic quadriparesis, and 9 (15\%) had hemiplegia.

In children with $\mathrm{CP}$ and control infants, GA ranged from 23 to $31.6 \mathrm{wk}$, with a median of $27.2 \mathrm{wk}$ in both groups (Table 1). Birth weights were similar in the two outcome groups, as was racial group (white/nonwhite). Private pay status and thyroid disorder were slightly more common in mothers of infants with CP. Clinical and placental histologic indicators of infection, including clinically diagnosed chorionitis, maternal fever in labor, maternal and fetal tachycardia, leukocytosis, and administration of antibiotics during the admission for delivery but before birth, and histologic evidence of placental inflammation, all were fairly frequent in these very preterm births but were observed in similar proportions of cases and controls. This observation is comparable to clinical findings in the larger study population from which this unselected subgroup was drawn (21).

Poor fetal growth, indicated by birth weight below the 10th percentile for GA for race and sex, was more frequent in control infants (Table 1). Respiratory distress syndrome or bronchopulmonary dyplasia and suspect or definite sepsis were slightly but not statistically significantly more frequent in children with CP. Neonatal infection (e.g. pneumonia, definite sepsis, meningitis) was observed in $37 \%$ of children with $\mathrm{CP}$ and $44 \%$ of control children. Repeated neonatal seizures were observed only in children with a later diagnosis of CP. A variety of medical and surgical treatments were observed with comparable frequency in cases and controls. 
Table 1. Maternal and infant characteristics, children with $C P$ and control children (means [SD] or number [\%])

\begin{tabular}{|c|c|c|c|c|}
\hline \multirow[b]{2}{*}{ Mothers } & \multicolumn{2}{|c|}{$\begin{array}{c}\mathrm{CP} \\
(N=64)\end{array}$} & \multicolumn{2}{|c|}{$\begin{array}{c}\text { Control } \\
(N=107)\end{array}$} \\
\hline & \multirow{2}{*}{\multicolumn{2}{|c|}{$28.1(7.0)$}} & & \\
\hline Age (y) & & & \multicolumn{2}{|c|}{$28.1(6.3)$} \\
\hline Parity & \multicolumn{2}{|c|}{$1.2(1.4)$} & \multicolumn{2}{|c|}{$1.3(1.4)$} \\
\hline Primiparous & 26 & $(43.3 \%)$ & 43 & $(41.8 \%)$ \\
\hline \multicolumn{5}{|l|}{ Race } \\
\hline White non-Hispanic & 27 & $(43.5 \%)$ & 36 & $(35.0 \%)$ \\
\hline White Hispanic & 15 & $(24.2 \%)$ & 30 & $(29.1 \%)$ \\
\hline Black & 15 & $(24.2 \%)$ & 31 & $(30.1 \%)$ \\
\hline Asian & 2 & $(3.2 \%)$ & 4 & $(3.9 \%)$ \\
\hline Other & 3 & $(4.8 \%)$ & 2 & $(1.9 \%)$ \\
\hline Private payment & 36 & $(64.3 \%)$ & 48 & $(48.0 \%)$ \\
\hline Maternal thyroid disorder & 5 & $(8.8 \%)$ & 2 & $(2.1 \%)$ \\
\hline Premature rupture of membrane & 28 & $(44.4 \%)$ & 43 & $(41.0 \%)$ \\
\hline Chorionitis, clinical & 20 & $(31.3 \%)$ & 29 & $(27.6 \%)$ \\
\hline Uterine tenderness & 15 & $(28.3 \%)$ & 13 & $(15.5 \%)$ \\
\hline Maternal fever $>37.7^{\circ} \mathrm{C}$ & 17 & $(26.6 \%)$ & 30 & $(28.0 \%)$ \\
\hline $\begin{array}{l}\text { Maternal tachycardia }>100 \\
\text { bpm }\end{array}$ & 13 & $(21.7 \%)$ & 21 & $(21.2 \%)$ \\
\hline Fetal tachycardia $>160 \mathrm{bpm}$ & 12 & $(20.0 \%)$ & 18 & $(18.4 \%)$ \\
\hline Elevated $\mathrm{WBC}>15,000 / \mathrm{mL}$ & 43 & $(70.5 \%)$ & 59 & $(57.8 \%)$ \\
\hline Predelivery antibiotics & 42 & $(65.6 \%)$ & 78 & $(74.3 \%)$ \\
\hline Antenatal corticosteroids & 41 & $(73.2 \%)$ & 68 & $(66.0 \%)$ \\
\hline None & 15 & $(26.8)$ & 35 & $(34.0)$ \\
\hline Single course & 33 & $(58.9)$ & 56 & $(54.4)$ \\
\hline Multiple courses & 8 & $(14.3)$ & 12 & $(11.7)$ \\
\hline Cesarean section & 25 & $(39.1 \%)$ & 42 & $(39.3 \%)$ \\
\hline Placenta to pathology & 41 & $(89.1 \%)$ & 81 & $(97.6 \%)$ \\
\hline Placental inflammation & 31 & $(70.5 \%)$ & 58 & $(68.2 \%)$ \\
\hline \multicolumn{5}{|l|}{ Infants } \\
\hline GA (wk) & \multicolumn{2}{|c|}{$27.2(2.5)$} & \multicolumn{2}{|c|}{$27.2(2.4)$} \\
\hline Birth weight $(\mathrm{g})$ & \multicolumn{2}{|c|}{$1093.9(363.4)$} & \multicolumn{2}{|c|}{$1074.0(343.7)$} \\
\hline Day of blood draw & \multicolumn{2}{|c|}{$2.4(3.8)$} & \multicolumn{2}{|c|}{$2.4(3.5)$} \\
\hline Male & 39 & $(63.9 \%)$ & 63 & $(59.4 \%)$ \\
\hline Growth retardation & 1 & $(1.7 \%)$ & 8 & $(7.5 \%)$ \\
\hline Sepsis & 26 & $(43.3 \%)$ & 34 & $(32.7 \%)$ \\
\hline Neonatal infection* & 21 & $(36.8 \%)$ & 44 & $(44.4 \%)$ \\
\hline Respiratory distress & 58 & $(96.7 \%)$ & 90 & $(87.4 \%)$ \\
\hline Patent ductus & 12 & $(20.0 \%)$ & 21 & $(20.4 \%)$ \\
\hline Neonatal seizures & 9 & $(14.1 \%)$ & 6 & $(5.6 \%)$ \\
\hline Multiple seizures $\dagger$ & 7 & $(10.9 \%)$ & 0 & $(0.0 \%)$ \\
\hline Blood transfusion & 5 & $(8.1 \%)$ & 12 & $(11.5 \%)$ \\
\hline Surfactant & 34 & $(55.7 \%)$ & 50 & $(47.2 \%)$ \\
\hline High-frequency ventilation & 7 & $(11.7 \%)$ & 7 & $(6.6 \%)$ \\
\hline
\end{tabular}

WBC, white blood cells.

* Includes pneumonia, meningitis, or definite sepsis.

$\dagger$ Fisher exact test $p<0.05$, differences for all other comparisons were not significant.

Concentrations of measured substances were not associated with GA within the range of GA included in this study or with racial group (white/nonwhite) or day of life on which blood was drawn. Mean values of TNF- $\alpha$ and other inflammatory markers were somewhat lower in boys than in girls in both cases and controls, and SD were larger in boys.

Infants whose concentrations of one inflammatory cytokine were relatively high also tended to have high levels of the other inflammatory markers. In 17 (10\%) of the 171 infants tested, TNF- $\alpha$ concentrations were $39 \mathrm{pg} / \mathrm{mL}$ or higher, and in these children concentrations of IL-1, IL-6, and IL-8 were also the highest measured. In the same 17 children, concentrations of IFN- $\gamma$ and the peptides VIP, substance P (SP), and calcitonin gene-related peptide were also relatively high. Most of these children also had relatively high levels of IL-9, GM-CSF, IFN- $\gamma$, and VEGF. Except for IL-8, concentrations of measured chemokines (regulated on activation normal T-cell expressed and secreted (RANTES), MIP-1A, MIP-1B, MIP-2, and monocyte chemotactic protein 1) were not related to levels of IL-1, IL-6, and TNF- $\alpha$.

The $10 \%$ of children with highest TNF- $\alpha$ concentrations all had diagnoses of respiratory distress syndrome or bronchopulmonary dysplasia, as did $91 \%$ of all of the very preterm infants in this study. Cytokine concentrations in the first days of life were not different in those in whom respiratory disorder resolved before they left the nursery as compared with those in whom lung disease persisted.

Cytokines and CP. As evaluated by recycling immunoaffinity chromatography, the mean concentrations, SD, median values, and ranges for all measured cytokines and related substances were similar in preterm children with $\mathrm{CP}$ and control infants (Table 2; Fig. 1). No significant differences between the outcome groups were observed for any measured substance, either overall or in two GA strata $(<27 \mathrm{wk}$ and 27-31.6 wk). Limiting consideration to children whose blood was drawn on or before day $3(n=113)$ or those who received no infusion of blood products before testing $(n=149)$ did not alter the result. No differences were observed in cytokine concentrations among the spastic CP subtypes (diplegia, hemiplegia, quadriplegia). No association was observed between inflammatory cytokine concentrations and maternal, placental, or neonatal indicators of infection, either in children with $\mathrm{CP}$ or in control children (Table 3).

In the additional 19 very preterm children with $\mathrm{CP}$ and 19 control children whose blood was examined by Luminex methods using Linco kits, and the 18 children with $\mathrm{CP}$ and 16 control children whose cytokines were measured using Upstate kits, there were also no significant differences in concentrations of cytokines between case and control children (Table 4). Values for some analytes were similar in the bead-based double-antibody assays using Linco and Upstate kits, whereas others differed; for some analytes, both differed from values as measured by recycling immunoaffinity chromatography, a single-antibody method (Table 2).

Cytokine concentrations, ultrasound abnormality, and CP. Among children with CP, 58 (91\%) had at least one cranial ultrasonographic examination during the nursery course and 42 $(66 \%)$ had two or more. Of control children, $101(94 \%)$ had at least one ultrasound evaluation and $79(74 \%)$ had two or more. In children with two or more evaluations, results often differed, with some early-identified lesions not reported in later evaluations and with appearance of newly described lesions in some. PVL, ventricular enlargement, and/or moderate or severe germinal matrix hemorrhage was observed at some time during the nursery course in 23 children with CP [40\% (23 of 58) of those with at least one evaluation] and in 18 control children (18\%; Fisher's exact test, $p=0.004)$.

Mean concentrations of inflammatory cytokines tended to be higher in children with one or more ultrasound abnormalities, both among children with $\mathrm{CP}$ and controls, compared with those whose imaging studies were read as normal. In a two- 
Table 2. Concentrations of cytokines and related substances in children with CP and control children as measured by recycling immunoaffinity chromatography

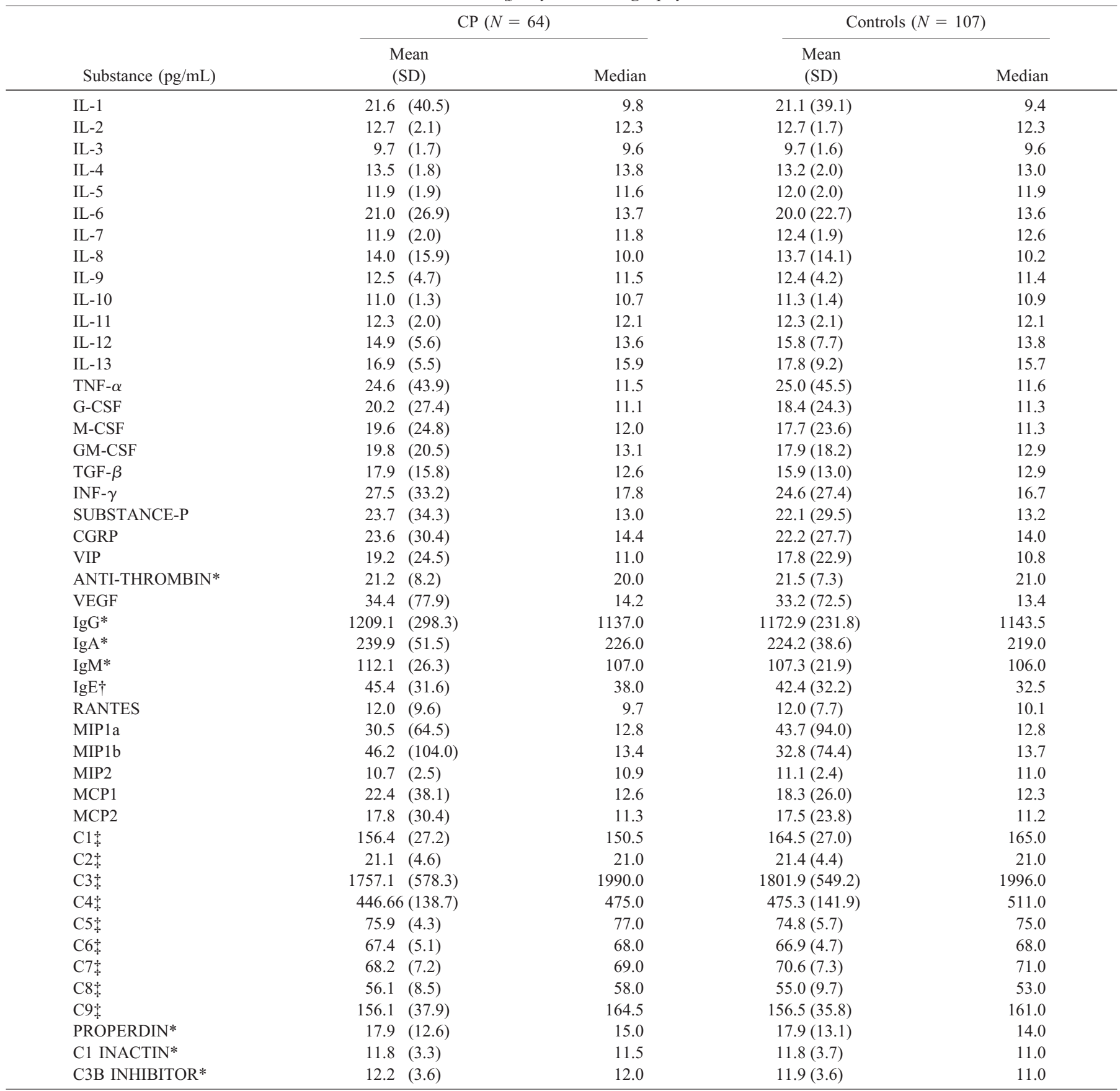

$* \mathrm{mg} / \mathrm{dL}, \dagger \mathrm{Iu} / \mathrm{dL}, \ddagger \mu \mathrm{g} / \mathrm{mL}$.

way ANOVA model with an interaction term, cytokine concentrations were significantly related to ultrasound abnormalities but not to diagnosis of CP. The 12 children, six with CP and six controls, who did not undergo ultrasound evaluation all had low concentrations of inflammatory cytokines.

Although there was some association of mean cytokine concentrations with ultrasound abnormalities, that association was not clinically predictive. For example, of the 17 children with highest observed levels of TNF- $\alpha$, six had neither neonatal ultrasound abnormalities nor later diagnosis of CP, four had ultrasound abnormalities but not $\mathrm{CP}$, three had $\mathrm{CP}$ but no identified ultrasound abnormality, and four had both ultrasound abnormality and CP.

\section{DISCUSSION}

Most surviving children who were born to nonpreeclamptic mothers before $32 \mathrm{wk}$ GA, regardless of whether they had imaging abnormalities on neonatal ultrasonography or had later $\mathrm{CP}$ diagnoses, had low concentrations of inflammatory cytokines and other inflammatory mediators in systemic blood during the first days of life. Levels of cytokines, measured by 


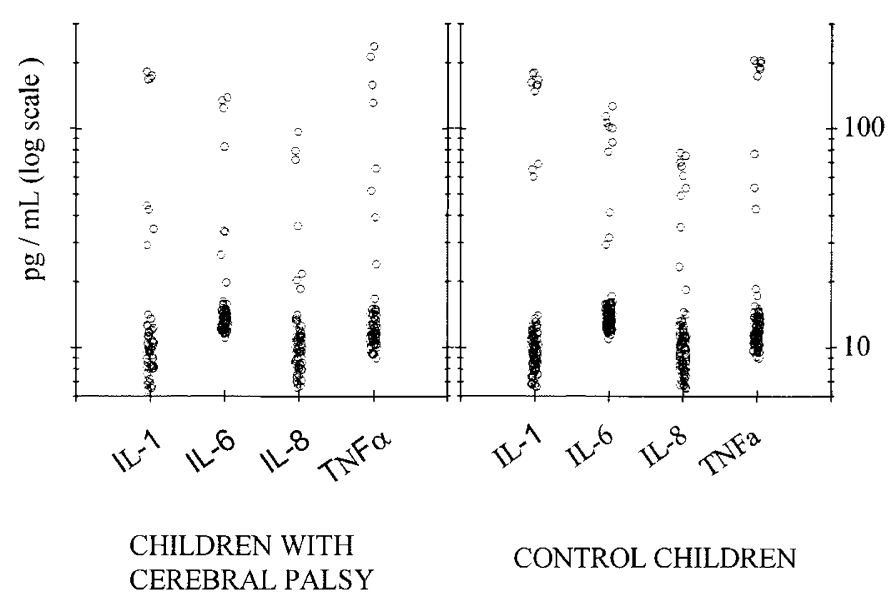

Figure 1. Concentrations in $\mathrm{pg} / \mathrm{mL}$ of IL-1, -6 , and -8 and TNF- $\alpha$ in 64 children with CP and 107 control children. The ordinate is a log scale. Values for individual children are indicated by circles.

the recycling immunoaffinity chromatography or by an alternative method, did not distinguish infants with later diagnoses of $\mathrm{CP}$ from control infants. That finding is unlike the observation in a predominantly term group of children previously reported (11). In the preterm children described in this report, as in the larger sample of which these children with measured cytokines were a subgroup (21) and in our earlier birth cohort of preterm infants (22), clinical and histologic indicators of inflammation were common but were not more common in children with later $\mathrm{CP}$ diagnosis than in control children. Of other investigators, some have and some have not found clinical indicators of inflammation to be associated with CP risk in very preterm infants (9), but a recent meta-analysis (27) concluded that the association is documented even in infants who are born preterm. Study populations and definitions vary considerably, however, raising questions as to the basic comparability of the component studies. For example, the frequency of clinically diagnosed chorioamnionitis for pregnancies ending before $32 \mathrm{wk}$ GA in these studies ranged from $3 \%$ to $59 \%$. In addition, the approach taken to adjusting for the powerful predictor of CP, GA, varies in different studies and can substantially influence results.

Cytokine concentrations were not related to day of life on which blood was drawn or to exposure to antenatal corticosteroids, antibiotics, or surfactant. There was no association, as there was in more mature infants (11), with clinical or histologic evidence of inflammation in mother or placenta.

Infants in whom the concentration of TNF- $\alpha$ was relatively high tended to have relatively high levels of other inflammatory markers. VEGF, a multifunctional cytokine with vascular growthenhancing and immunologic properties, inducible by inflamma-

Table 3. Concentrations of $T N F-\alpha(\mathrm{pg} / \mathrm{mL})$ in children with CP and controls (mean [SD])

\begin{tabular}{|c|c|c|c|c|c|c|c|c|}
\hline & \multicolumn{4}{|c|}{$\mathrm{CP}$} & \multicolumn{4}{|c|}{ Control } \\
\hline & $\mathrm{n}$ & YES & $\mathrm{n}$ & NO & $\mathrm{n}$ & YES & $\mathrm{n}$ & NO \\
\hline \multicolumn{9}{|l|}{ Maternal } \\
\hline Fever & 17 & $16.3(11.7)$ & 47 & $27.6(50.6)$ & 37 & $30.1(53.6)$ & 77 & $23.0(42.1)$ \\
\hline $\mathrm{WBC}>15,000 \mathrm{pcm}$ & 43 & $26.8(50.0)$ & 14 & $21.3(30.3)$ & 59 & $21.6(40.1)$ & 43 & $31.1(54.1)$ \\
\hline Steroids & 41 & $29.0(51.1)$ & 15 & $19.6(33.1)$ & 68 & $21.9(38.2)$ & 35 & $32.7(58.9)$ \\
\hline Tachycardia & 13 & $18.9(18.0)$ & 47 & $24.6(47.6)$ & 21 & $20.7(42.2)$ & 78 & $27.5(48.5)$ \\
\hline \multicolumn{9}{|l|}{ Placental } \\
\hline Inflammation & 31 & $26.6(44.9)$ & 13 & $21.2(34.4)$ & 58 & $33.0(56.5)$ & 27 & $17.8(33.0)$ \\
\hline \multicolumn{9}{|l|}{ Infant } \\
\hline Tachycardia & 12 & $29.0(58.4)$ & 48 & $21.1(38.5)$ & 18 & $37.3(57.7)$ & 80 & $23.7(44.7)$ \\
\hline Sepsis & 26 & $18.4(25.4)$ & 34 & $29.4(55.4)$ & 34 & $30.9(52.4)$ & 70 & $22.7(42.5)$ \\
\hline Infection & 21 & $29.2(53.7)$ & 36 & $17.4(25.6)$ & 44 & $27.2(48.8)$ & 55 & $25.3(46.1)$ \\
\hline
\end{tabular}

In two-way ANOVA models with an interaction term for each of the clinical factors, there were no significant effects for either CP or the clinical factors. PPROM, prolonged premature rupture of membranes.

Table 4. Mean concentrations (SD) of cytokines in children with CP and control children as measured by commercially available bioassay systems

\begin{tabular}{|c|c|c|c|c|}
\hline \multirow{2}{*}{$\begin{array}{l}\text { Substance } \\
(\mathrm{pg} / \mathrm{mL})\end{array}$} & \multicolumn{2}{|c|}{ Linco } & \multicolumn{2}{|c|}{ Upstate } \\
\hline & $\mathrm{CP}$ & CONTROL & $\mathrm{CP}$ & CONTROL \\
\hline$N$ & 19 & 19 & 18 & 16 \\
\hline IL-2 & $7.7(8.1)$ & $8.4(8.6)$ & & \\
\hline IL-4 & $12.1(18.5)$ & $6.7(6.1)$ & $1.1(2.3)$ & $0.5(1.0)$ \\
\hline IL-5 & $2.7(2.7)$ & $3.6(3.1)$ & & \\
\hline IL-6 & $34.9(62.6)$ & $111.1(353.9)$ & $126.1(345.1)$ & $10.9(15.9)$ \\
\hline IL-12 & $1.4(3.4)$ & $4.7(4.2)$ & $1.5(3.0)$ & $0.1(0.4)$ \\
\hline $\mathrm{TNF} \alpha$ & $2.8(1.5)$ & $3.0(0.9)$ & $1.0(2.4)$ & $1.0(2.2)$ \\
\hline $\mathrm{INF} \gamma$ & $4.8(4.0)$ & $5.3(4.6)$ & & \\
\hline GM-CSF & $9.3(4.1)$ & $9.3(3.2)$ & $1.2(2.4)$ & $0.9(1.5)$ \\
\hline
\end{tabular}


tory cytokines $(28,29)$ and by hypoxia $(30)$, was present in relatively high concentration in the $10 \%$ of infants with highest levels of IL-1, -6 , and -8 and TNF- $\alpha$. VIP and IL-9 levels were also relatively high in these infants. Cytokine levels, when high, might reflect overproduction of cytokines or their impaired degradation or clearance. Unlike the more mature infants previously reported (10), in these preterm infants, concentrations of chemokines other than IL-8 did not parallel the inflammatory IL.

Many studies of infection in pregnancy and outcome in preterm infants have used neonatal ultrasound findings as an end point. As in other studies of preterm infants, we found ultrasound abnormalities to be more common in infants who later had a CP diagnosis. Ultrasound data are not a strong point of this study, however; ultrasound examinations were not performed by study design but reflect medical practice in 22 hospitals in a geographic region over a 7-y period. We did not undertake independent review of ultrasound findings but accepted the clinical reports, and we lack detailed information on the size, position, and timing of ultrasonographically identified brain lesions. Ultrasonographic findings changed over the nursery stay in many infants. Six children with $\mathrm{CP}$ were never scanned, and 36 children with normal early scans were not rescanned. Despite these limitations, common to many observational studies of cranial ultrasound in preterm infants, we found that neonatal concentrations of inflammatory cytokines were higher, on average, in infants with ultrasound abnormalities.

$\mathrm{CP}$, the major outcome of this study, was well ascertained and was not related to neonatal cytokine concentrations. Because levels of neonatal cytokines averaged higher in infants with ultrasound abnormalities and ultrasound abnormalities were associated with $\mathrm{CP}$, it may be surprising that neonatal cytokine levels were not higher in infants with later CP diagnoses than in control infants. Several factors may contribute to this apparent paradox. The relationship of ultrasound to $\mathrm{CP}$ was not powerful: a majority of children with $\mathrm{CP}(60 \%)$ did not have evidence of ultrasonographic abnormalities, whereas one in six control children (18\%) did. Children who were never scanned had low cytokine levels. The relationship between cytokine concentrations and ultrasound findings, although statistically significant, does not provide predictability. There are apparently routes to $\mathrm{CP}$ in very preterm infants other than via ultrasound-recognized white matter disorders or major hemorrhage, and inflammatory cytokines may not play the role in $\mathrm{CP}$ in very preterm infants that has been postulated.

The lack of association of indicators of infection, clinical (21) or molecular, with CP in preterm infants in this study contrasts with the identification of such an association, both clinical and molecular, with $\mathrm{CP}$ in more mature infants (11, 12). Immune function is different in mothers and in fetuses across the second half of gestation. Different microorganisms tend to colonize the maternal reproductive tract at different GA, immunologic responses mature over the course of gestation, and there are differential vulnerabilities of components of the brain during its development. There may be real differences in how immune and neurobiologic characteristics are interrelated in very preterm as compared with more mature infants.

Measured in neonatal blood an average of $2.4 \mathrm{~d}$ after birth by recycling immunoaffinity chromatography or flow analysis methods, inflammatory cytokines examined in this study did not distinguish children with later $\mathrm{CP}$, born before $32 \mathrm{wk}$ GA to nonpreeclamptic mothers, from control children. These data do not support the hypothesis that inflammatory cytokines in the early days of life are important in producing or predicting $\mathrm{CP}$ in very preterm infants or suggest that it would be beneficial to target these multifunctional molecules in efforts to prevent adverse neurologic outcome.

Acknowledgments. Dr. Li Xia Yang, LDN/NICHHD, assisted in setting up the protein determinations. This study would not have been possible without the cooperation of the California Children's Medical Services Branch, Department of Health Services, the local California Children's Services programs, and the California Department of Developmental Services. Newborn blood specimens were provided by the Genetic Disease Branch of the Department of Health Services, whose decision to archive these valuable specimens has contributed to many scientific investigations.

\section{REFERENCES}

1. Goncalves LF, Chaiworapongsa T, Romero R 2002 Intrauterine infection and prematurity. Ment Retard Dev Disabil Res Rev 8:3-13

2. Paul VL, Dawar R, Gupta SD, Singh M, Buckshee K, Gupta U, Bhan MK, Bhargava VL, Takkar K, Deorari AK 1998 Histologic chorioamnionitis and its association with prematurity in a hospital-based study. Indian J Med Res 108:272-278

3. Guinn D, Gibbs RS 2002 Infection-related preterm birth: a review of the evidence. Neoreviews 3:386-396

4. Goldenberg RL, Rouse DJ 1998 Prevention of premature birth. N Engl J Med 339:313-320

5. Cummins SK, Nelson KB, Grether JK, Velie EM 1993 Cerebral palsy in four northern California counties, births 1983 through 1985. J Pediatr 123:230-237

6. Murphy DJ, Hope PL, Johnson A 1997 Neonatal risk factors for cerebral palsy in very preterm babies: case-control study. BMJ 314:404-408

7. Nelson KB, Ellenberg JH 1986 Antecedents of cerebral palsy: multivariate analysis of risk. N Engl J Med 315:81-86

8. Grether JK, Nelson KB 1997 Maternal infection and cerebral palsy in infants of normal birthweight. JAMA 278:207-211

9. Walstab J, Bell R, Reddihough D, Brennecke S, Bessell C, Beischer N 2002 Antenatal and intrapartum antecedents of cerebral palsy: a case-control study. Aust N Z J Obstet Gynaecol 2:138-146

10. Nelson KB, Willoughby RE 2000 Infection, inflammation and the risk of cerebral palsy. Curr Opin Neurol 13:133-139

11. Nelson KB, Dambrosia JM, Grether JK, Phillips TM 1998 Neonatal cytokines and coagulation factors in children with cerebral palsy. Ann Neurol 44:666-675

12. Foster-Barber A, Ferriero DM 2002 Neonatal encephalopathy in the term infant: neuroimaging and inflammatory cytokines. Ment Retard Dev Disabil Res Rev $8: 20-24$

13. Yoon BH, Jun JK, Romero R, Park KH, Gomez R, Choi J-H, Kim I-O 1997 Amniotic fluid inflammatory cytokines (interleukin- 6 , interleukin- $1 \beta$, and tumor necrosis factor- $\alpha$ ), neonatal brain white matter lesions, and cerebral palsy. Am J Obstet Gynecol 177:19-26

14. Yoon BH, Romero R, Park JS, Kim CJ, Kim SH, Choi J-W, Han TR 2000 Fetal exposure to an intra-amniotic inflammation and the development of cerebral palsy at the age of three years. Am J Obstet Gynecol 182:675-681

15. Baud O, Foix-L'helias L, Kaminski M, Audibert F, Jarreau P-H, Papiernik E, Huon C, Lepercq J, Dehan M, Lacaze-Masmonteil T 1999 Antenatal glucocorticoid treatment and cystic periventricular leukomalacia in very premature infants. N Engl J Med 341:1190-1196

16. Duggan PJ, Maalouf EF, Watts TL, Sullivan MHF, Counsell SJ, Allsop J, Al-Nakib L, Rutherford MA, Battin M, Roberts I, Edwards AD 2001 Intrauterine T-cell activation and increased proinflammatory cytokine concentrations in preterm infants with cerebral lesions. Lancet 358:1699-1670

17. Minagawa K, Tsuji Y, Ueda H, Koyama K, Tanizawa T, Okamura H, HashiimotoTamaoki T 2002 Possible correlation between high levels of IL-18 in the cord blood of pre-term infants and neonatal development of periventricular leukomalacia and cerebral palsy. Cytokine 17:164-170

18. Kitchen WH, Doyle LW, Ford GW, Rickards AL, Lissenden JV, Ryah MM 1987 Cerebral palsy in very low birthweight infants surviving to 2 years with modern perinatal intensive care. Am J Perinatol 4:29-35

19. Nelson KB, Grether JK 1995 Can magnesium sulfate reduce the risk of cerebral palsy in very low birthweight infants? Pediatrics 95:263-269

20. Redline RW, Wilson-Costello D, Borawski E, Fanaroff AA, Hack M 1998 Placental lesions associated with neurologic impairment and cerebral palsy in very low-birthweight infants. Arch Pathol Lab Med 122:1091-1099 
21. Grether JK, Nelson KB, Walsh E, Willoughby RE, Redline RW 2003 Intrauterine exposure to infection and risk of cerebral palsy in very preterm infants. Arch Pediatr Adolesc Med 157:26-32

22. Grether JK, Nelson KB, Emery III ES, Cummins SK 1996 Prenatal and perinata factors associated with cerebral palsy in very low birthweight infants. J Pediat 128:407-414

23. Phillips TM, Krum JM 1998 Recycling immunoaffinity chromatography for multiple analyte analysis in biological samples. J Chromatogr B Biomed Sci Appl 715:55-63

24. Phillips TM, Dickens BF 2000 Affinity and Immunoaffinity: Purification Techniques BioTechnique Books, Eaton Press, Natick, MA

25. Vignali DA 2000 Multiplexed particle-based flow cytometric assays. J Immunol Methods 243:243-255

26. Prabhakar U, Eirikis E, Davis HM 2002 Simultaneous quantification of proinflammatory cytokines in human plasma using the LabMap assay. J Immunol Methods 260:207-218
27. Wu YW, Colford Jr JM 2000 Chorioamnionitis as a risk factor for cerebral palsy: a meta-analysis. JAMA 284:1417-1424

28. Ryuto M, Ono M, Izumi H, Yoshida S, Weich HA, Kohno K, Kuwano M 1996 Induction of vascular endothelial growth factor by tumor necrosis factor alpha in human glioma cells. Possible roles of SP-1. J Biol Chem 271:2822028228

29. Webb NJA, Myers CR, Watson CJ, Bottomley MJ, Brenchley PEC 1998 Activated human neutrophils express vascular endothelial growth factor (VEGF). Cytokine 10:25425-25427

30. Berse B, Hunt JA, Diegel RJ, Morganelli P, Yeo K-T, Brown F, Fava RA 1999 Hypoxia augments cytokine (transforming growth factor-beta) and IL-1)-induced vascular endothelial growth factor secretion by human synovial fibroblasts. Clin Exp Immunol 115:176-182 